\title{
Epidemiologic and Molecular Characterization of Zoonotic Dermatophytes from Pet Dogs and Cats in Egypt
}

\author{
Mohamed Ali Ibrahim, Gihan Kamal Abdel-Latef, Mohamed Mahmoud Abdel Rahim*, \\ Sahar Abdel Aleem Abdel Aziz
}

Department of Hygiene, Zoonoses and Epidemiology, Faculty of Veterinary Medicine, Beni-Suef University, BeniSuef, Egypt.

\begin{abstract}
Dermatophytosis is a zoonotic worldwide public health issue caused by pathogenic fungi called dermatophytes, belonging to three genera; Microsporum $(M)$, Trichophyton $(\mathrm{T})$, and Epidermophyton $(\mathrm{E})$. Such disease is transmitted to man through contact with the infected animals. This study investigated the prevalence of dermatophytes in pet dogs and cats, besides humans in Cairo, Giza, and Beni-Suef governorates, Egypt. Skin scrapings were taken from 245 pet dogs, 180 cats, and 60 humans. A direct microscopy, fungal culture, and molecular analysis were carried out. The results revealed that the prevalence of dermatophytes was $20.4,16.1$, and $31.6 \%$ in dogs, cats, and humans, respectively. $M$. canis was the most frequent isolated from dogs (10.2\%) followed by T. mentagrophytes (6.1\%) and T. verrucosum (4.0\%). whereas the unique dermatophyte found in cats was $M$. canis (8.3\%). The study revealed that outdoor housed animals showed higher rates of infection than indoor breeds. Concerning age, puppies showed higher susceptibility (50.0\%) than juvenile and adult dogs. In relation to, allergic dermatitis, it was found that the diseased dogs and cats showed higher isolation rates than apparently healthy ones. Shifting to human cutaneous infections, the findings denoted that $M$. canis was the highest zoonotic potential $(20.0 \%)$ whereas $T$. verrucosum was not determined in the screened samples. Furthermore, people aged (11-30) years, as well as pet workers, were the most infected groups. Surprisingly, $80.0 \%$ of the individuals who suffered from dermal infections and/or alopecia were cult positive for dermatophytes. PCR amplification of dermatophyte using CHS1 primers yielded a fragment of about $440 \mathrm{bp}$ while with ITS1 primer yielded a $700 \mathrm{bp}$, the isolated $M$. canis was subjected for sequencing analyses and deposited in the gene bank. It was concluded that the occurrence of dermatophytes in dogs and cats along with high the prevalence of $M$. canis in humans suggesting the potentiality of zoonotic spread.
\end{abstract}

Keywords | Dermatophytes, Molecular characterization, Dogs, Cats, M. canis, Zoonoses

Received | June 04, 2021; Accepted | July 28, 2021; Published | November 15, 2021

*Correspondence | Mohamed M. Abdel Rahim, Assistant Lecturer of Zoonoses and Epidemiology, Department of Hygiene, Zoonoses and Epidemiology, Faculty of Veterinary Medicine, Beni-Suef University, Beni-Suef, Egypt; Email: m.abdelrahim@vet.bsu.edu.eg

Citation | Ibrahim MA, Abdel-Latef GK, Abdel-Rahim MM, Aziz SAAA (2021). Epidemiologic and molecular characterization of zoonotic dermatophytes from pet dogs and cats in Egypt. Adv. Anim. Vet. Sci. 9(12): 2225-2233.

DOI | http://dx.doi.org/10.17582/journal.aavs/2021/9.12.2225.2233

ISSN (Online) | 2307-8316; ISSN (Print) | 2309-3331

Copyright $\odot 2021$ Ibrahim et al. This is an open access article distributed under the Creative Commons Attribution License, which permits unrestricted use, distribution, and reproduction in any medium, provided the original work is properly cited.

\section{INTRODUCTION}

$\mathrm{C}$ utaneous fungal infections of both humans and animals represent the most predominant mycoses universally with a relatively high economic significance (Gupta et al., 2017; Gnat et al., 2020). Dermatophytes are a unique group of filamentous keratinophilic fungi having the capacity to invade keratinized structures of the epidermis in both humans and animals, producing superficial cutaneous infections named ringworm or tinea (Hagag et al., 2017). Dermatophytosis is one of the most common communicable mycotic diseases with extreme public health potential (Ivaskiene et al., 2016). Although more than 30 species of dermatophytes have been well-known the utmost frequently associated ones with ringworm are belong to three main genera; Trichophyton, Microsporum, 
and Epidermophyton (Mattei et al., 2014). The globally distributed species of dermatophytes are Microsporum canis, Trichophyton verrucosum, and Trichophyton mentagrophytes. Humans especially those in close contact with animal facilitate are the highest susceptible group for infection either through direct or indirect transmission (Parmar eand Dhami, 2007; Samanta, 2015).

The ultimate significance of the ringworm relies on its contagiousness among the affected communities, the economic impact of treatment, the difficulty of control measures, as well as the great public health consequences, since the majority of dermatophytes isolated from animals are of zoonotic issues (Chermette et al., 2008; Bahri, 2013). Moreover, many domestic animals could carry the infectious spores on their coats that could be transmitted to man and animals by direct or indirect contact (Moreillo et al., 2017).

Pet dogs and cats represent a foremost role in the transmission of dermatophytes primarily $M$. canis, that is considered a highly contagious and potentially pathogenic for both animals and humans, particularly where the unhygienic environmental standards, among the children, elderly patients, and immunocompromised individuals (Cabañes, 2000; Seyedmousavi et al., 2015). Dermatophytosis represented the most common petassociated and occupational zoonotic disease with a specific high rate of infection among pediatric and geriatric patients due to the immaturity of the host immune response (Sahni et al., 2018).

The diagnosis of dermatophytosis is unreliable based on clinical signs exclusively, owing to the variable nature of the dermatological findings in addition to, the similarity of other skin diseases that mimic the characteristic dermatophyte lesions. Mycological culture remains the gold standard for the diagnosis of dermatophytoses and the only method for the phenotypic identification of their species (Chermette et al., 2008). In addition, molecular diagnostic techniques provided simple and precise tools for dermatophyte species characterization besides phylogenetic analysis; including sequencing of the large submit $r R N A$ gene, the chitin synthase-encoding gene, and sequencing of the internal transcribed spacer (ITS) regions (Kano et al., 2000; Ninet et al., 2003; Kaszubiak et al., 2004; Sharma et al., 2006; Rezaei-Matehkolaei et al., 2013; Kabbashi et al., 2016).

Although dermatophyte infections are well-known in Egypt, their prevalence has not been well clarified as the disease is un-notifiable and many infections are treated with over-the-counter drugs. Taking into account the increasing impact of these infections, the numerous hardships in their treatments, so the current study highlighted to recognize the prevalence of dermatophyte infection among various categories of pet dogs and cats, investigate the prevalence of zoonotic cutaneous mycoses of humans in contact with the examined animals as well as, molecular characterization for the isolates using the gene- specific chitin synthase 1 (CHS1) and the internal transcribed spacers (ITS) of ribosomal DNA gene (rDNA) using the ITS regions of ribosomal DNA gene (rDNA).

\section{MATERIALS AND METHODS}

\section{ETHICAL APPROVAL}

Under the supervision of the International Animal Care and Use Committee (IACUC) and the Institutional Review Board (IRB) of Beni-Suef University in Egypt, all animals and human samples collected during this investigation were processed in accordance with the IACUC and IRB's approval number (IACUC, 021-166).

\section{StUdy Design}

This study was carried out during the period from July 2018 to September 2019 in Cairo, Giza, and Beni-Suef governorates, Egypt. A total of 245 canines and 180 cats, as well as 60 in-contact human samples, were examined.

\section{SAMPLES OF PET DOGS AND CATS}

Cutaneous samples were collected from household dogs $(n=160)$ and cats $(n=125)$ that underwent clinical examination in different veterinary clinics, besides samples from 35 pet shop dogs, 50 samples from military dogs obtained from the Veterinary Hospital for Laboratory Treatment and Analysis, Cairo, Egypt, and 55 samples from outdoor cats. Skin scrapings of crusts and loosely attached scales were removed and the underlying surface was well-cleaned with $70 \%$ alcohol, then placed in clean plastic cups, then transported to the Laboratory of Animal Hygiene and Zoonoses Department, Faculty of Veterinary Medicine, Beni-Suef University, for dermatologic examination for the presence of dermatophytes of public health significance.

\section{Human samples}

Dermatologic samples were obtained from pet owners $(n=40)$ and pet shop workers $(n=20)$. Skin scrapings were collected from 15 diseased patients showing lesions of ringworm as tinea capitis or tinea corporis, as well as 45 cutaneous samples from asymptomatic people in close contact with pet animals. Each sample was carefully labeled and sent to the laboratory where the fungal examination was initiated.

\section{LABORATORY PROCEDURES}

MCROSCOPIC EXAMINATION

Skin scrapings of crusts, loosely attached scales, and 
hair plugs were carefully removed under strict hygienic measures, then placed on a clean slide, gently mixed with $10 \% \mathrm{KOH}$ and $40 \%$ Dimethyle sulphoxide (DMSO) in an equal proportion, covered with a coverslip, heated gently and left for at least 30 minutes to 1 hour. The prepared slides were thoroughly examined using both low power (10X) and high power (40X) magnification for the presence of hyphae and/or arthroconidia. The appearance of spores on the surface of the shaft of infected hair showing a mosaic arrangement (ectothrix infection) or hyphal fragments and arthroconidia were seen internally (endothrix infection) (Shalaby et al., 2016).

\section{ISOLATION AND IDENTIFICATION OF DERMATOPHYTES}

The collected hair scales and crusts are cultured on Sabouraud's dextrose agar (SDA (Oxoid, UK)) supplemented with chloramphenicol $(500 \mathrm{mg} / \mathrm{L})$, cycloheximide $(400 \mathrm{mg} / \mathrm{L})$, thiamine $(10 \mathrm{mg} / \mathrm{L})$ and inositol $(50 \mathrm{mg} / \mathrm{L})$. Cultures were incubated aerobically at room temperature $\left(25^{\circ} \mathrm{C}\right)$ for up to 4 weeks. Positive cultures were examined both macroscopically (color of the surface and reverse, texture and topography) and microscopically using lactophenol-cotton blue wet mounts (type of conidia that appeared either, small unicellular microconidia or larger septate macroconidia) for species identification. In the absence of any growth after 4 weeks the culture was considered negative (Chermette et al., 2008).

\section{MoleCUlAR CHARACTERIZATION}

\section{DNA EXTRACTION OF THE ISOLATED SPECIES}

The freshly grown fungal colonies and hyphae were harvested from the SDA surface then they were frozen at $-80^{\circ} \mathrm{C}$ for DNA extraction using QIAamp DNeasy Plant Mini kit (Catalogue No. 69104, QIAGEN, Germany) following the manufacturer's instructions.

\section{PCR USING (ITS 1) DNA SEQUENCING AND ANALYSIS}

Two PCR runs were conducted using two sets of primers. The first primer set flanked 440 base pairs (bp) of the Chitin synthase genes (CHS 1) (Cafarchia et al., 2009). The second set of primers is specific for the ITS 1 gene (Luo and Mitchell, 2002). The data of primer sequences is shown in Table 1. PCR amplification was performed using a PCR master mix (Emerald Amp GT PCR master mix (Takara) Code No. RR310A) in a total volume of $25 \mu \mathrm{l} /$ reaction. The PCR cycling condition was illustrated in Table 2. The PCR amplicons were analyzed by running $20 \mu \mathrm{l}$ of the PCR products on a $1.5 \%$ agarose gel stained with ethidium bromide $(0.5 \mu \mathrm{g} / \mathrm{mL})$ in comparison with a DNA ladder (100bp), (Gel Pilot 100 bp ladder, Code No. 239035 supplied from QIAGEN, Germany). Under UV illumination using a gel documentation and analysis system, the gel was photographed.

The amplified $700 \mathrm{bp}$ PCR products were purified using a QIAquick PCR Product extraction kit. (QIAGEN, Valencia). The Bigdye Terminator V3.1 cycle sequencing kit (Perkin Elmer) was used for the sequence reaction and then it was purified using the Centrisep spin column. DNA sequences were obtained by Applied Biosystems 3130 genetic analyzer (HITACHI, Japan), a BLAST ${ }^{\circledR}$ analysis (Basic Local Alignment Search Tool) (Altschul et al., 1990) was initially performed to establish sequence identity to gene bank accessions. The phylogenetic tree was created by the MegAlign module of Laser gene DNA Star version 12.1 (Thompson et al., 1994), and Phylogenetic analysis was done using maximum likelihood, neighborjoining, and maximum parsimony in MEGA6 (Tamura et al., 2013).

\section{STATistical AnAlysis}

The obtained data was expressed descriptively using percentages for the prevalence of zoonotic ringworm infections, while the Chi-square test was used to determine the risk factors associated with the prevalence of dermatophytes in the examined dogs and cats, including age, breed, and gender. Findings were considered significant at $P<0.05$.

\section{RESULTS AND DISCUSSION}

Pet dogs and cats play a major role in the transmission of dermatophytes species, especially $M$. canis, which is considered the most contagious and potentially pathogenic species for both humans and animals. Based on microscopic, cultural isolation, and identification, the overall prevalence

Table 1: Oligonucleotide primers sequences specific for molecular characterization of the isolated dermatophytes.

\begin{tabular}{|c|c|c|c|c|}
\hline Gene & & Sequence & Amplified product & References \\
\hline \multirow[t]{2}{*}{ Chs-1 } & Forward & $\begin{array}{l}\text { DMTFchsF1 } \\
\text { CGAGTACATGTGCTCGCGCAC }\end{array}$ & About $440 \mathrm{bp}$ & Cafarchia et al., (2009) \\
\hline & Reverse & $\begin{array}{l}\text { DMTFchsR1 } \\
\text { CGAGGTCAAARGCACGCCAGAG }\end{array}$ & & \\
\hline \multirow[t]{2}{*}{ ITS } & Forward & $\begin{array}{l}\text { ITS1 } \\
\text { TCCGTAGGTGAACCTGCGG }\end{array}$ & $\begin{array}{l}\text { Variable (including } 700 \\
\text { bp) }\end{array}$ & Luo and Mitchell, (2002) \\
\hline & Reverse & $\begin{array}{l}\text { ITS4 } \\
\text { TCC TCC GCT TAT TGA TAT GC }\end{array}$ & & \\
\hline
\end{tabular}

December 2021 | Volume 9 | Issue 12 | Page 2227 
of the isolated dermatophytes was $20.40 \%$ and $16.11 \%$ in the examined dogs and cats respectively, as shown in Table 2. This current data was highly matched to those reported by Gallupi et al. (2013) and Debnath et al. (2015), who recorded a prevalence of $20.0 \%$ and $20.93 \%$, respectively, in the examined dogs, whereas results obtained from cultivated feline samples were higher (30.0 and 37.33\%, respectively) than the present study findings. On the other hand, a higher isolation rate $(55.95 \%)$ was determined by Roshanzamir et al. (2016) in Baku, Azerbaijan in the examined dogs, whereas a lower prevalence (14.4\%) of dermatophyte recovery was recorded by Seker and Dogan (2011) in the west of Turkey.

Table 2: Prevalence of cultivated dermatophyte species in the examined dogs, cats and humans.

\begin{tabular}{|llll|}
$\begin{array}{l}\text { Dermatophyte } \\
\text { species }\end{array}$ & $\begin{array}{l}\text { Pet dogs } \\
(\mathbf{n = 2 4 5})\end{array}$ & $\begin{array}{l}\text { Pet cats } \\
(\mathbf{n = 1 8 0})\end{array}$ & $\begin{array}{l}\text { Humans } \\
(\mathbf{n = 6 0})\end{array}$ \\
\hline M. canis & $25(10.2 \%)$ & $15(8.3 \%)$ & $12(20 \%)$ \\
\hline T. mentagrophytes & $15(6.1 \%)$ & $10(5.5 \%)$ & $7(11.6)$ \\
T. Verrucosum & $10(4.0 \%)$ & $4(2.2 \%)$ & $(0.0 \%)$ \\
Total & $50(20.40 \%)$ & $29(16.11 \%)$ & $19(31.6 \%)$
\end{tabular}

As experimented in the current study, $M$. canis was the highest cultivated dermatophyte species from pet dogs and cats' samples (10.2 and 8.3\%, respectively), followed by $T$. mentagrophytes, then T. Verrucosum, in a descending order. Similar findings were reported by Ivaskiene et al. (2016); Parmar et al. (2018), and Dworecka-Kaszak et al. (2020) who concluded that $M$. canis was the main fungal species causing ringworm in pet dogs, cats as well as humans. These current results confirmed the significant transmission of the isolated dermatophytes in both animal and human samples, suggesting the high potentiality of zoonotic transmission of $M$. canis from pet dogs and cats to humans either by direct contact or contact with contaminated environment. Therefore, clinicians and mycologists should incorporate hygienic measures during dealing with infected species (Sı̆̆ırc1 et al., 2019).

Multifactorial agents affecting the occurrence of cutaneous dermatophytosis, including the age of affected animals, revealed that young aged animals less than 6 months were the most susceptible in both examined dogs and cats (50.0 and 33.3\%, respectively) as denoted in Table 3. Such results were in harmony with Seker and Dogan (2011) and Ivaskiene et al. (2016) who stated that young animals are more susceptible to dermatophyte infection than older ones owing to the undeveloped immune system and the response of the examined animals and humans at this period of life, especially at younger and pediatric ages, as well as the physiological and pathological situation of the hair and skin, especially the fungistatic sebum deficiency of such animals (Moosavi et al., 2019). In relation to the dog's gender, comparable results were introduced by Natale et al. (2007) and Hagag et al. (2017) in Egypt, who stated that male gender is a major predisposing factor for dermatophyte infection owing to the higher number of male dogs examined in our study.

A higher isolation rate was detected mainly from outdoor dogs and cats that were reared in pet animal facilities (41.17 and 32.72\%) than household ones (9.37 and 8.8\%) respectively, as denoted in Table 3. Such obtained data was parallel to that achieved by Copetti et al. (2006) and Yamada et al. (2019), which implies that outdoor transmission acted as a major infection route for ringworm. This could be referred to the unsanitary conditions as well as the high stocking density in such places, as well as the fungal spores cross contamination between healthy animals and diseased ones with skin mycosis which confirms the natural route of dermatophyte infection especially with $M$. canis as assumed by Minnat and Khalaf (2019).

With respect to pet animal breeds, the current study reported that the local breeds expressed a higher infection rate with dermatophytes in both dogs and cats (48.1 and $26.66 \%)$ in comparison to that of the exotic breeds (16.98 and 14\%) on frequency. This misconception can be justified by the fact that native breeds are allowed to travel freely rather than foreign ones, which are confined to movement and restricted to certain areas, which put the local breeds in contact with other diseased or carrier animals or contaminated environments.

Regarding the skin health status of the examined pets, it was denoted that the affected animals showed a higher isolation rate of dermatophytes (25.3 and $47.5 \%)$ than those with apparently healthy skin (12.63 and 7.14\%) in both pet dogs and cats, respectively. That forementioned finding was supported by Copetti et al. (2006), who reported that dermatophytes were commonly isolated from animals with cutaneous signs than from asymptomatic animals. Such a result could be explained considering the concept that healthy skin usually acts as a barrier for fungal infection, but traumatic skin lesions, scratching, and itching due to ectoparasite infection facilitate the fungal invasion, as explained by Morettie et al. (2013). Moreover, the carrier state of dermatophytes was previously recorded by Frymus et al. (2013), and Ilhan et al. (2016) whose study declared that pet dogs and cats can act as carriers of fungal spores and the disease condition occurred under certain predisposing factors.

Shifting to dermatophyte infection in the examined human samples, as denoted in Table 4, it was reported that the overall prevalence of infection was (31.16\%). Such data came in accordance with, Parmer et al. (2018), who 
isolated dermatophytes from human samples at a rate of $33.33 \%$. In contrast, a lower infection percent (6.7\%) was recorded by Murmu et al. (2015). The high isolation rate of dermatophytes in this study may be attributed to the low level of hygiene, habitat, and the immune status of both examined humans and animals, which can promote dermatophyte infection as denoted by Chaitanya et al. (2013).

Referring to the gender of examined people, data from Table 4 showed that individuals aged 11-30 years and children less than 10 years were most affected $(33.3 \%$ and $25.7 \%$, respectively). Such findings came in agreement with Ngwogu and Otokunefor (2007) and Murmu et al. (2015), who revealed that male patients were more affected than females. Furthermore, the current results denoted that pet workers were more susceptible to infection than household owners $(50.0 \%$ vs $22.5 \%)$. Such findings were in line with those of Sakar and Dogan (2011), Moriello et al. (2017), and Saraiva (2017), who asserted that dermatophytosis is a pet-associated zoonosis caused by direct or indirect contact with deposited hair and scales in the environment.

Human affections with dermatophytes may induce different types of skin lesions, varying from discrete superficial scaling to deep inflammatory infiltration. In this study, out of 15 examined diseased individuals who had complaints of skin affection and/or alopecia, 12 patients (80\%) were positive for ringworm. In contrast, out of 45 asymptomatic tested people, only 7 persons (15.5\%) showed dermatophytes infection. Considering the lesion caused by dermatophytes in the examined humans, $M$. canis was the most prominent isolated species followed by T. mentagrophytes, whereas $T$. verrucosum was not determined in the screened samples.
The obtained results were in accordance with those found by Arenas (2015) and Yamada et al. (2019) who found that M. canis was responsible for $60-95 \%$, respectively of tinea capitis in human cases. This suggested data revealed that zoonotic transmission of dermatophytes from dogs and cats to their owners was previously reported by Kobayashi et al. (2013), and Takeda et al. (2018). Furthermore $M$. canis was considered one of the most significant zoophilic fungi affecting animals, mainly dogs and cats, and can be transmitted to humans by direct contact or indirectly through contaminated environments, as reported by Taha (2011).

Due to nonspecific opportunistic fungal development, phenotypic identification of dermatophytes is not always precise, and traditional diagnosis is a time-consuming. For the diagnosis and identification of dermatophytes, opposing molecular characteristic approaches usually provide swift, highly sensitive, and specific results. Table 5 clarified this information, demonstrating that molecular assays appeared to be the superior tool in the diagnosis of dermatophyte infection (20.2\%), followed by traditional culture methods (15.7\%) and finally wet mount preparation with $\mathrm{KOH}(13.4 \%)$.

Table 1 showed that molecular PCR amplification was extracted from 5 phenotypic isolated dermatophyte samples divided as 2 samples from pet dogs, 2 samples from pet cats, and 1 human sample using two sets of primers; (CHS1) primer which yielded a fragment of about 440 bp and (ITS1) primer that yielded a fragment of $700 \mathrm{bp}$ revealed $100 \%$ genetically positive for Microsporum species (Figure 1).

Table 3: Risk factors associated with the prevalence of dermatophytes in the examined dogs and cats.

\begin{tabular}{lllllll} 
Variable & \multicolumn{3}{c}{ Dogs (n=245) } & \multicolumn{3}{c}{ Cats (n=180) } \\
& No. examined & No. positive & $\%$ & No. examined & No. positive & \% \\
Age (months) & & & & & & \\
$<6$ & 60 & 30 & 50.0 & 60 & 20 & 33.3 \\
$>6-12$ & 50 & 13 & 26.0 & 65 & 7 & 10.76 \\
$>12$ & 130 & 7 & 5.38 & 55 & 2 & 3.63 \\
Gender & & & & & \\
Males & 145 & 35 & 24.13 & 70 & 10 & 14.28 \\
Females & 100 & 15 & 15.0 & 110 & 19 & 17.27 \\
Residence & & & & & & \\
Households & 160 & 15 & 9.37 & 125 & 11 & 8.8 \\
Outdoors & 85 & 53 & 41.17 & 55 & 18 & 32.72 \\
Breeds & & & & & & \\
Exotic & 218 & 37 & 16.98 & 150 & 21 & 14.0 \\
Local & 27 & 13 & 48.1 & 30 & 8 & 26.66 \\
Skin Status & & & & & & \\
Healthy skin & 95 & 12 & 12.63 & 140 & 10 & 7.14 \\
Allergic-dermatitis & 150 & 38 & 25.3 & 40 & 19 & 47.5
\end{tabular}


Table 4: Prevalence and risk factors associated with zoophilic dermatophytes in the examined humans.

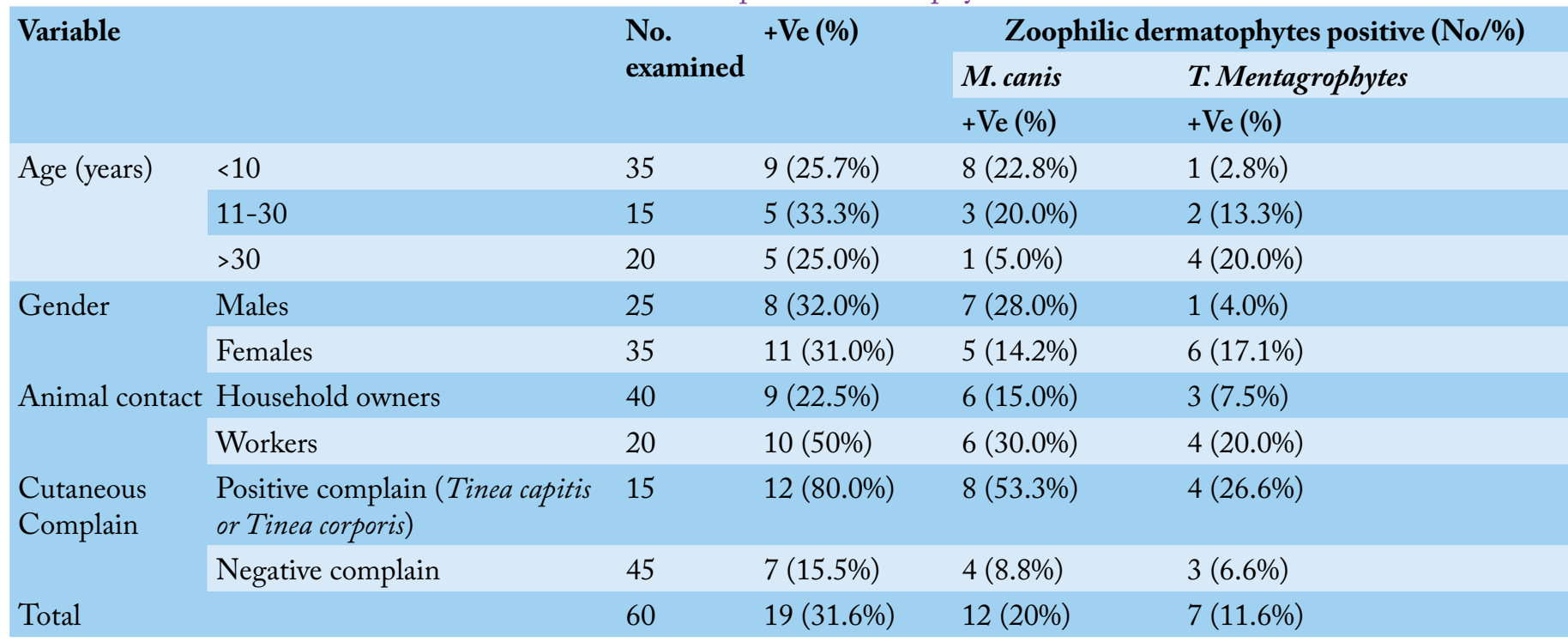

Table 5: Comparison of wet mount preparation using $\mathrm{KOH}$, traditional Culturing and PCR results among the different examined species.

\begin{tabular}{llllllll} 
Sample source & No. examined & \multicolumn{2}{c}{ KOH results } & \multicolumn{2}{c}{ Culture results } & \multicolumn{2}{c}{ PCR results } \\
& & No. positive & $\%$ & No. positive & $\%$ & No. positive & $\%$ \\
Dogs & 245 & 35 & 14.3 & 40 & 17.1 & 50 & 100.0 \\
Cats & 180 & 18 & 10.0 & 22 & 12.2 & 29 & 100.0 \\
Humans & 60 & 12 & 20.0 & 14 & 23.3 & 19 & 100.0 \\
Total & 485 & 65 & 13.4 & 76 & 15.7 & 98 & 20.2
\end{tabular}

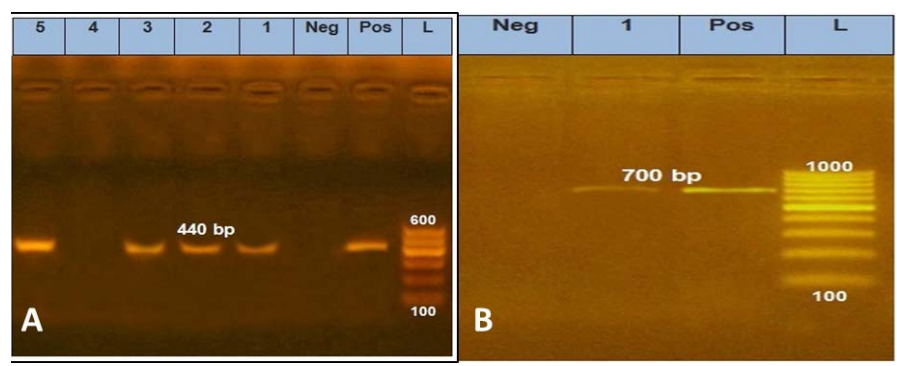

Figure 1: PCR amplification of genomic DNA sampling carried out for $p c h-1$ DNA region using specific primers DMTF CHSF1 and DMTFCHSR1.

Lane1-2: M. canis from cat Samples, Lane 3: M. canis from dog samples, Lane 5: $M$. canis from human sample. B, ITS1 specific primer yielded a 700bp.

Based on sequence comparisons and the nucleotide variation magnitude of the genetic locus ITS. The sequence of each locus should allow the identification of dermatophytes to be identified down to the specific genotype level. In this investigation, sequence identity was discovered in one cluster of genes from Microsporum spp., which included $M$. canis. The sequence was aligned and deposited in the Gene Bank with the accession number MW425860 (Figure 2). The $M$. canis sequence obtained in this study (accession number $=$ MW425860) shared 100 percent nucleotide and amino acid identities with AJ000619.1 (Microsporum canis var. distortum) isolated from clinical samples in Berlin,
Germany (Grăser et al., 1999), according to sequencing analysis of the internal transcribed spacers (ITS) gene. The zoophilic fungus $M$. canis var. distortum infects dogs, cats, and other animals. It is the causative agent of tenia capitis in New Zealand, Australia, and North America. Infected hair showed an ectothrix infection and bright green-yellow fluorescence under Woods ultra-violet light (Grăser et al., 1999). Comparative sequence analysis revealed that $M$. canis isolate was closely related to $M$. canis AJ000626.1 (Grăser et al., 1999), M. canis JN134109.1,JN134123.1, and JN134119.1 from clinical isolates in Tehran, Iran (RezaeiMatehkolaei et al., 2013), and M. canis AY213657.1 from the United States (Rakeman et al., 2005), with significant nucleotide identity ranged from $98.7 \%$ to $99.4 \%$.

\section{CONCLUSIONS AND RECOMMENDATIONS}

It was concluded that dermatophytes, predominantly $M$. canis, were recovered from canine and feline ringworm and that dogs/cats kept in groups and those wandering freely had increased dermatophyte isolation. Furthermore, human infection could arise as a result of interaction with symptomatic and/or asymptomatic carrier animals. Additionally, molecular techniques acted as a standard method for diagnosis of dermatophytes giving full data on 
the genetic characteristics of dermatophyte strains which can be valuable in future investigations.

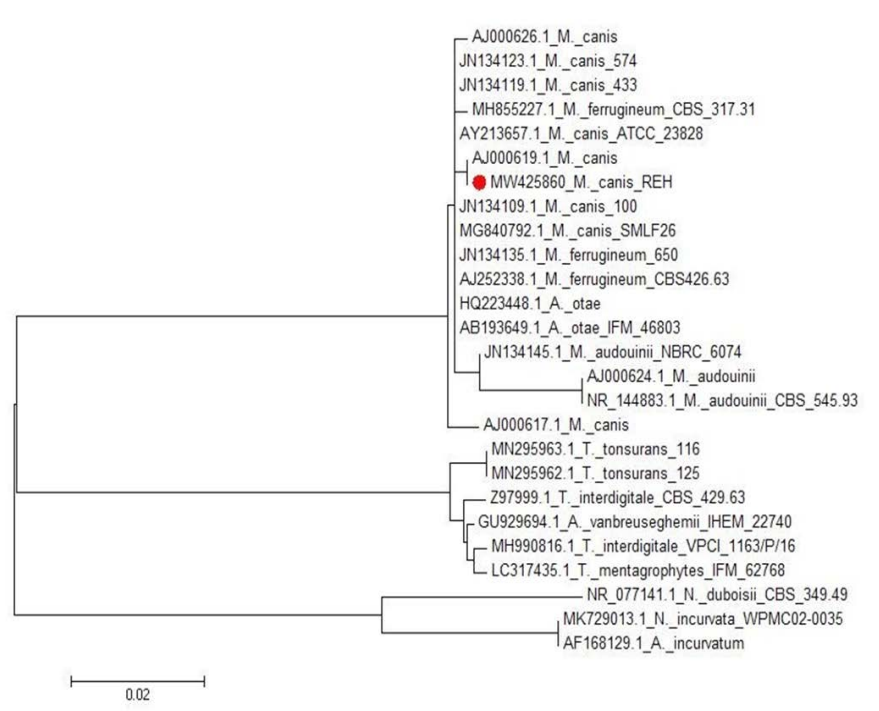

Figure 2: Phylogenetic analysis of CHS1 and ITS. Sequence data representing the $M$. canis isolated from examined pets. The bar representing the genetic distance is drawn to scale. The single asterisk represents sequence that determined in this study. The other sequences were obtained from Gene Bank.

\section{NOVELTY STATEMENT}

This study Investigated the prevalence of zoonotic cutaneous mycoses of both pet dogs and cats, and humans in contact with especially young children in Egypt, as well as Studying inter- and intra-specific genomic variations for molecular identification of clinically important dermatophyte species obtained from clinical specimens using PCR technique with specific sequencing of Egyption novel zoonotic dermatophyte (M. canis_REH) and representing at Gene Bank.

\section{AUTHOR'S CONTRIBUTION}

MAI, GKAL, SAAAA perform the study scheme, writing, reviewing, and editing. MMAR emphasizes fungal isolation and identification, writing, reviewing, and editing.

\section{CONFLICT OF INTEREST}

The authors have declared no conflict of interest.

\section{REFERENCES}

-Altschul SF, Gish W, Miller W, Myers EW, Lipman DJ (1990). Basic local alignment search tool. J. Mol. Biol., 215: 403410. https://doi.org/10.1016/S0022-2836(05)80360-2

-Arenas R (2015). Micología Médica Ilustrada (5 $5^{\text {th }}$ Edtn). Mc Graw Hill Companies, México. pp. 67-98.
- Bahri J (2013). Dermatofitoses: Causas e Tratamento. Monografia (Trabalho de Conclusão de Curso- TCC). Centro Universitário CESMAC, Curitiba.

- Cabanes FJ (2000). Dermatophytes in domestic animals. Rev. Iberoamer. Micol., 17: 104-108.

- Cafarchia C, Romito D, Sasanelli M, Lia R, Capelli G, Otranto D (2004). The epidemiology of canine and feline dermatophytoses in southern Italy. Mycoses, 47: 508-513. https://doi.org/10.1111/j.1439-0507.2004.01055.x

- Cafarchia C, Otranto D, Weigl S, Campbell BE, Parisi A, Cantacessi C, Mancianti F, Danesi P, Gasser RB (2009). Molecular characterization of selected dermatophytes and their identification by electrophoretic mutation scanning. Electrophoresis, 30: 3555-3564. https://doi.org/10.1002/ elps.200900313

- Chaitanya VS, Lavania M, Nigam A, Turankar RP, Singh I, Horo I, Sengupta U, Jadhava RS (2013). Cortisol and proinflammatory cytokine profiles in Type 1 (reversal) reactions of leprosy. Immunol. Lett., 156(1-2): 159-167. https://doi. org/10.1016/j.imlet.2013.10.008

- Chermette R, Ferreiro L, Guillot J (2008). Dermatophytoses in animals. Mycobatologia, 166: 385-405. https://doi. org/10.1007/s11046-008-9102-7

- Copetti MV, Santurio JM, Cavalheiro AS, Boeck AA, Argenta JS, Aguiar LC, Alves SH (2006). Dermatophytes isolated from dogs and cats suspected of dermatophytosis in Southern Brazil. Acta Sci. Vet., 34: 119-124. https://doi. org/10.22456/1679-9216.15173

- Debnath C, Mitra T, Kumar A, Samanta I (2015). Detection of dermatophytes in healthy companion dogs and cats in eastern India. J. Vet. Res., 17(1): 20-24.

-Dworecka-Kaszak B, Biegańska MJ, Dąbrowska I (2020). Occurrence of various pathogenic and opportunistic fungi in skin diseases of domestic animals: A retrospective study. BMC Vet. Res., 16: 248. https://doi.org/10.1186/s12917020-02460-x

- Frymus T, Gruffydd-Jones T, Pennisi MG, Addie D, Belak S, Boucraut-Baralon C, Egberink H, Hartmann K, Hosie MJ, Lloret A, Lutz H, Marsilio F, Mostl K, Radford AD, Thiry E, Truyen U, Hornizek MCD (2013). Dermatophytosis in cats: ABCD guideline on prevention and management. J. Feline. Med. Urg., 15: 598-604. https:// doi.org/10.1177/1098612X13489222

- Galluppi P, Leveque JFC, Beghelli V, Bonoli C, Mattioli M, Ostanello F, Tampieri MP, Accorsi PA (2013). Cortisol levels in cat's hair in presence or absence of Microsporum canis infection. Res. Vet. Sci., 95(3): 176-1080. https://doi. org/10.1016/j.rvsc.2013.07.023

- Gnat S, Łagowski D, Nowakiewicz A (2020). Major challenges and perspectives in the diagnostics and treatment of dermatophyte infections. J. Appl. Microbiol., 129: 212-232. https://doi.org/10.1111/jam.14611

- Grăser Y, El-Fari M, Vilgalys R, Kuijpers AF, De Hoog GS (1999). Phylogeny and taxonomy of the family Arthrodermataceae (dermatophytes) using sequence analysis of the ribosomal ITS region. Med. Mycol. 37(2): 105-114. https://doi.org/10.1080/02681219980000171

- Gupta AK, Foley KA, Versteeg SG (2017). New antifungal agents and new formulations against dermatophytes. Mycopathologia, 182: 127-141. https://doi.org/10.1007/ s11046-016-0045-0

- Haggag YN, Samaha HA, Nossair MA, Mohammad RMH (2017). Prevalence of dermatophytosis in some animals and 
humans in Bahera Province, Egypt. Alex. J. Vet. Sci., 53(2): 64-71. https://doi.org/10.5455/ajvs.203688

-Indarjulianto S, Yanuartono, Widyarini S, Rahajo S, Purnamaningsih H, Nururrozi A, Hariwibowo N, Jainudin HA (2017). Microsporum canis infection in dermatitis cats. J. Vet., 18(2): 207-210. https://doi.org/10.19087/ jveteriner.2017.18.2.207

-Ilhan Z, Karaca M, Ekin IH, Solmaz H, Akkan HA, Tutuncu, M (2016). Detection of seasonal asymptomatic dermatophytes in van cats. Br. J. Manage., 47(1): 225-230. https://doi. org/10.1016/j.bjm.2015.11.027

-Ivaskiene M, Matusevicius AP, Grigoniss A, Zamokas G, Babickaite L (2016). Efficacy of tropical therapy with newly developed terbinafine and econazole formulations in the treatment of dermatophytosis in cats. Pol. J. Vet. Sci., 19(3): 535-543. https://doi.org/10.1515/pjvs-2016-0067

-Kabbashi MA, Omer AA, Enan KA (2016). Genotyping of dermatophytes isolated from dermatophytoses sudanese patients. Afr. J. Med. Sci., 1(2): 1(2): 1-8.

-Kano R, Okabayashi K, Nakamura Y, Ooka S, Kashima M, Mizoguchi M, Watanabe S, Hasegawa A (2000). Differences among chitin synthase I gene sequences in Trichophyton rubrum and T. violaceum. Med. Mycol., 38: 47-50. https:// doi.org/10.1080/mmy.38.1.47.50

- Kaszubiak A, Klein S, de Hoog GS, Graser Y (2004). Population structure and evolutionary origins of Microsporum canis, $M$. ferrugineum and M. audouinii. Infect. Genet. Evol., 4: 179186. https://doi.org/10.1016/j.meegid.2003.12.004

-Kobayashi H, Yoshioka M, Anzawa K, Mochizuki T (2013). Cases of Microsporum canis infection between 2005-2011 in a dermatology clinic in the southern part of Kanazawa City. Skin Res., 12: 219-233.

-Luo G, Mitchell TG (2002). Rapid identification of pathogenic fungi directly from cultures by using multiplex PCR. J. Clin. Microbiol., 40: 2860-2865. https://doi.org/10.1128/ JCM.40.8.2860-2865.2002

- Mattei AS, Beber MA, Madrid IM (2014). Dermatophytosis in Small Animals. SOJ Microbiol. Infect. Dis. 2(3): 1-6. https://doi.org/10.15226/sojmid/2/3/00124

- Miller WH, Craig EG, Campbell KL, Muller GH, Scott DW (2013). Muller and Kirks small animal dermatology. $7^{\text {th }}$ ed. St. Louis: Elsiver, 2013.

-Minnat RT, Khalaf MJ (2019). Epidemiological, Clinical and Laboratory study of Canine Dermatophytosis in Baghdad Governorate, Iraq. The Iraqi Journal of Veterinary Medicine, 43(1):183 - 196.

- Moretti A, Agnetti F, Manciati F, Nardoni S, Righi C, Moretta I, Morganti G, Papini M (2013). Dermatophytosis in animals: Epidemiological, clinical and zoonotic aspects. G. Ital. Dermatol. Venereol., 148: 563-72.

- Moriello AK, Coynert K, Paterson S, Mignon B (2017). Diagnosis and treatment of dermatophytosis in dogs and cats. Vet. Dermatol., 28: 266-288. https://doi.org/10.1111/ vde. 12440

- Moosavi A, Ghazvini RD, Ahmadikia K, Hashemi SJ, Geramishoar M, Mohebali M, Yekaninejad MS, Bakhshi H, Khodabakhsh M (2019). The frequency of fungi isolated from the skin and hair of asymptomatic cats in rural area of Meshkin-shahr-Iran. J. Mycol. Med., 29: 14-18. https://doi. org/10.1016/j.mycmed.2019.01.004

- Murmu S, Debnath C, Pramanik AK, Mitra T, Jana S, Dey S, Banerjee S, Batabyal K (2015). Detection and characterization of zoonotic dermatophytes from dogs and cats in and around Kolkata. Vet. World, 8(9): 1078-1082. https://doi.org/10.14202/vetworld.2015.1078-1082

- Natale A, Regalbono AFd, Zanellato G, Cavalletto M, Danesi P, Capelli G, Pietrobelli M (2007). Parasitological survey on stray cat colonies from the Veneto Region. Vet. Res. Commun., 31(1): 241-244. https://doi.org/10.1007/ s11259-007-0015-6

- Ngwogu AC, Otokunefor TV (2007). Epidemiology of dermatophytosis in rural community in Eastern Nigeria and review of literature from Africa. Mycopathologia, 164: 149158. https://doi.org/10.1007/s11046-007-9038-3

- Ninet B, Isabell J, Bontems O, Lechenne B, Jousson O, Panizzon R, Lew D, Monod M (2003). Identification of dermatophyte species by $28 \mathrm{~S}$ ribosomal DNA sequencing with a commercial kit. J. Clin. Microbiol., 41: 826-830. https://doi.org/10.1128/JCM.41.2.826-830.2003

- Parmar BC, Dhami AJ (2007). Incidence and management of dermatophytosis (ringworm) in young calves. Indian J. Field Vet., 2(3): 50-52.

- Parmar BC, Nayak JB, Brahmbhatt MN, Chaudhary JH, Patel A Gida HK (2018). Prevalence of Dermatophytosis in animals and human's population with special reference to its zoonotic significance. Int. J. Pure App. Biosci., 6(5): 687691. https://doi.org/10.18782/2320-7051.6991

- Rakeman JL, Bui U, Lafe K, Chen YC, Honeycutt RJ, Cookson BT (2005). Multilocus DNA sequence comparisons rapidly identify pathogenic molds. J. Clin. Microbiol., 43(7): 33243333. https://doi.org/10.1128/JCM.43.7.3324-3333.2005

- Rezaei-Matehkolaei A, Makimura K, De Hoog S, Shidfar MR, Zaini F, Eshraghian M, Naghan PA, Mirhendi H (2013). Molecular epidemiology of dermatophytosis in Tehran, Iran, a clinical and microbial survey. Med. Mycol., 51(2): 203-207. https://doi.org/10.3109/13693786.2012.686124

- Roshanzamir H, Naserli S, Ziaie B, Fakour M (2016). Incidence of dermatophytes isolated from dogs and cats in the city of Baku, Azerbaijan. Comp. Clin. Pathol., 25(2): 327-329. https://doi.org/10.1007/s00580-015-2185-x

-Sahni K, Singh S, Dogra S (2018). Newer topical treatments in skin and nail dermatophyte infections. Indian Dermatol. Online J., 9(3): 149-158.

-Samanta (2015). Veterinary mycology. $1^{\text {st }}$ Edn. India: Springer. 16 pp. https://doi.org/10.1007/978-81-322-2280-4

- Saraiva ST (2017). Epidemiologia e diagnóstico de dermatofitose em humanos e animais: uma abordagem "One Health". Dissertação de Mestrado em Biotecnologia para as Ciências da Saúde. pp. 79.

- Seker E, Dogan N (2011). Isolation of dermatophytes from dogs and cats with suspected dermatophytosis in Western Turkey. Prev. Vet. Med., 98: 46-51. https://doi.org/10.1016/j. prevetmed.2010.11.003

-Seyedmousavi S, Guillot J, Tolooe A, Verweij PE, De Hoog GS (2015). Neglected fungal zoonoses: hidden treats to man and animals. Clin. Microbiol. Infect., 21(5): 416-425. https://doi.org/10.1016/j.cmi.2015.02.031

- Shalaby MF, Nasr E1-din A, Abu E1-Hamd M (2016). Isolation, identification, and in vitro antifungal susceptibility testing of dermatophytes from clinical samples at Sohag University Hospital in Egypt. Electron. Phys., 8(6): 2557-2567.https:// doi.org/10.19082/2557

- Sharma R, Rajak RC, Pandey AK, Graser Y (2006). Internal transcribed spacer (ITS) of rDNA of appendaged and non-appendaged strains of Microsporum gypseum reveals Microsporum appendiculatum as its synonym. Antonie Van 
Leeuwenhoek. 89: 197-202. https://doi.org/10.1007/ s10482-005-9018-x

- Sı̆̆ırcı BD, Metiner K, Çelik B, Kahraman B, Ikis S, Bagcigil AF, Ozgur NY, Seyall AK (2019). Dermatophytes isolated from dogs and cats suspected dermatophytoses in Istanbul, Turkey within a 15-year-period: An updated report. Kocatepe Vet. J., 12(2): 116-121.

-Taha M (2011). Dermatophytosis. In: Medical mycology: atlas of medically important fungi and dermatomycosis. Cairo: Mecca Printing House. ISBN: Egypt, pp. 24983-2010.

- Takeda K, Anzawa K, Mochizuki T, Yamada S, Kobayshi H, Kimora S (2018). Infant case of tinea faciei caused by Microsporum canis. J. Dermatol., 45: 187-188. https://doi. org/10.1111/1346-8138.14242

- Tamura K, Stecher G, Peterson D, Filipski A, Kumar S (2013). MEGA6: Molecular evolutionary genetics analysis version 6.0. Mol. Biol. Evol., 30: 2725-2729. https://doi. org $/ 10.1093 / \mathrm{molbev} / \mathrm{mst197}$

-Thompson JD, Higgins DG, Gibson TJ (1994). CLUSTAL W: improving the sensitivity of progressive multiple sequence alignment through sequence weighting, position-specific gap penalties and weight matrix choice. Nucl. Acids Res., 22(22): 4673-4680. https://doi.org/10.1093/nar/22.22.4673

- Yamada S, Anzawa K, Mochizuki T (2019). An epidemiological study of feline and canine Dermatophytoses in Japan. Med. Mycol.J., 60(2): 39-44.https://doi.org/10.3314/mmj.19.001 